\title{
A Hybrid of Sliding Mode Control and Fuzzy Gain Scheduling PID Control using Fuzzy Supervisory Switched System for DC Motor Speed Control System
}

\author{
Husain Ahmed $^{1}$ and Abha Rajoriya ${ }^{2}$ \\ ${ }^{1}$ Reasearch Scholar, Mewar University, Gangrar, Rajasthan, India; \\ ${ }^{2}$ Head \& Prof. Deptt. Of EEE, Jai Naraiyan College Of Engg \& Tech. \\ Bhopal,MP,India; \\ 'husainahmed@rediffmail.com \\ 2 abharajoriya@gmaill.com
}

\begin{abstract}
This paper shows another way to deal with speed control of DC Motor. Two nonlinear controllers, one of sliding mode control and the other Fuzzy gain scheduling PID, characterize another control structure. Essentially, in this configuration procedure, the SMC and Fuzzy gain scheduling PID controller have been consolidated by a switching system which is chosen by the Fuzzy supervisory system. The sliding-mode controller acts essentially in a transient state while the fuzzy gain scheduler PID controller acts in the steady state. The new structure epitomizes the favorable circumstances that both nonlinear controllers offer: a sliding-mode controller provides the fast rise time and fuzzy gain scheduling PID controllers lessening the chattering in the steady state. The simulation results show that utilizing the new hybrid SMC fuzzy gain scheduling PID controller gives "better" system response as far as transient and steady state are concerned when compared with the SMC or fuzzy gain scheduling PID controller's applications. The controller parameters are tuned with the help of fuzzy logic.
\end{abstract}

Keywords: sliding mode control SMC, Fuzzy gain scheduling based control FGSPID, hybrid control, DC Motor

\section{Introduction}

Traditional control plan like PID Controllers is viewed as the standard control structures and fuzzy controllers have situated themselves as a partner of established PID controllers on the same prevailing part at the information rich range [1]. PID controllers are intended for linear system and they give an ideal cost effective system. On the other hand, the presence of nonlinear effects confines their performances. Fuzzy controllers are effective connected to nonlinear system on account of their knowledge based nonlinear characteristics to accomplish smooth control during switching. Hybridization exploits the helpful sides of both classifications. Normally different hybrid controller structures have been emerged in writing [2], [3]. A fuzzy switching strategy between fuzzy controller and ordinary PID controllers is utilized to accomplish smooth control during switching [4].

In a few applications, these two control structures are consolidated by a switch [5], [6], [7]. Another scheme of combining SMC and PI-like FLC with the help of expert TakagiSugino type inference mechanism shown in literature [8].

DC motors are widely used in robotic and industrial equipment where high accuracy is needed. In some cases the uncertain conditions encounter the DC motor control to some difficulties. D.C motor is considered as a SISO (Single Input and Single Output) system which has speed characteristics and is compatible with most mechanical loads [9]. By using terminal voltage control method a D.C motor can be controlled over a wide range of 
speed. The main drawbacks of the linear control approach are the sensitivity in performance to the system parameters variations and inadequate rejection of external perturbations and load changes. To face these problems, variable-structure control based approaches, such as sliding-mode control (SLMC), or fuzzy logic based control (FLBC), have been recently applied to the control of electrical drive systems. SLMC has been shown to be an effective way for controlling electric drive systems. It is a robust control because the high-gain feedback control input cancels nonlinearities, uncertainty parameters, and external disturbances. On the other hand, this control strategy offers some drawbacks associated with the large torque chattering that appears in a steady state, which may excite mechanical resonance.

Fuzzy-logic, first proposed by L. A. Zadeh, has recently received a great deal of attention. The easy way of defining a fuzzy controller by rules with an obvious physical meaning has helped to expand this control technique. When it is applied to control nonlinear systems, this nonlinear control strategy has shown better results than classical controllers do.

This paper presents a new hybrid fuzzy sliding-mode controller for the speed regulation of a DC motor. SLMC mostly acts in a transient state, providing a fast dynamic response and enlarging the stability limits of the system, while the FGSPIDC acts mainly in steady state to reduce chattering. Hybridization of these two controller structures gives idea quickly to endeavor the valuable sides of both classes. If we compare this approach to a classical SMC controller, steady-state performance is enhanced.

\section{DC Motor Model}

DC motor represents the simplest DC drive system. Figure. 6 represents the structure of the electrical circuit of a DC motor.

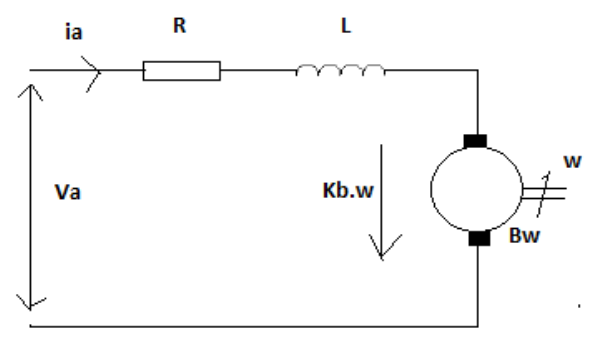

Figure 1. DC Motor Model

The motor dynamics are governed by two coupled first-order equations with respect to armature current and shaft speed [10]:

$L \frac{d i}{d t}=u-R i-K_{e} w$

$J \frac{d w}{d t}=k_{m} i-B w$

Where, $L$ represents the armature inductance, $R$ the armature resistance, $i$ the armature current, ke the back EMF constant, w the shaft angular velocity, J the moment of inertia, $\mathrm{B}$ the coefficient of viscous friction, $\mathrm{km}$ the motor torque constant, $u$ the terminal armature voltage.

The demand is that the shaft angular velocity should track a desired trajectory.

Let $w^{*}(t)$ represents a desired velocity and $e=w^{*}-w$ tracking error. If we choose the variables $x_{1}=e$ and $x_{2}=\dot{e}$ as state space variables, then the system can be described with the following equations: 
$\dot{x_{1}}=x_{2}$
$\dot{x_{2}}=-\frac{R}{L} x_{2}-\frac{k_{m} k_{e}+B}{J L} x_{1}-\frac{k_{e}}{J L} u+\ddot{w}_{r}+\frac{R}{L} \dot{w}_{r}+\frac{k_{m} k_{e}+B}{J L} w_{1}$

For the second order system, we can characterize switching function as:

$s=\rho x_{1}+x_{2}=\rho x_{1}+\dot{x_{1}}$

$\rho$ Shows a positive constant.

\section{Sliding Mode Control}

The design of a variable structure sliding mode controller consists of two phases:

I. Sliding (switching) surface design so as to attain the desired system response, like the stability to the origin, when forced to stay on the surface.

II. Selecting feedback gains of the controller so that the closed-system is stable to the sliding surface.

While in sliding mode the system shows the following characteristics. In particular:

I. The system is not affected by unmodeled uncertainties.

II. The system dynamics is represented by a reduced set of differential equations.

This technique is known as the order reduction and very helpful in designing variable structure sliding mode controllers [11] [12].

In order to derive the sliding surface for SISO, consider the system in its controller companion form,

$\dot{x}=\left[\begin{array}{ccccc}0 & 1 & 0 & \ldots & 0 \\ 0 & 0 & 1 & \ldots & 0 \\ \vdots & \vdots & \vdots & \ldots & \vdots \\ 0 & 0 & 0 & \ldots & 1 \\ -a_{0} & -a_{1} & -a_{2} & \ldots & -a_{n-1}\end{array}\right] x+\left[\begin{array}{c}0 \\ 0 \\ \vdots \\ 0 \\ 1\end{array}\right] u$

The aim is to find a control signal such that given a desired state $w^{*}$, the tracking error $w^{*}-w$ maintain to zero even the, model uncertainties and unmodeled disturbances, present [11]. With the tracking error defined as:

$e=w^{*}-w$

Let the sliding surface be:

$s(x)=\sigma e$

$=\left[\begin{array}{lllll}\sigma_{1} & \sigma_{2} & \ldots & \sigma_{n-1} & 1\end{array}\right]\left[\begin{array}{c}e_{1} \\ \vdots \\ e_{n}\end{array}\right]$

$=\sigma_{1} e_{1}+\sigma_{2} e_{2}+\cdots+\sigma_{n-1} e_{n-1}+e_{n}$

$=0$

To avoid loss of generality, assumed that $\sigma_{n}=1$. If this was not the case, divide both sides of $\sigma e=0$ by $\sigma_{n} \neq 0$ to ensure that $\sigma_{n}=1$. So, above equation is written as:

$e_{n}=-\sigma_{1} e_{1}-\sigma_{2} e_{2}-\cdots-\sigma_{n-1} e_{n-1}$

Now combine the equations of the plant model and that of the sliding surface. First note that

$\dot{e}_{n-1}=e_{n}$

Hence it can be written as

$$
\dot{e}_{1}=e_{2}
$$




$$
\dot{e}_{2}=e
$$

$\dot{e}_{n-1}=-\sigma_{1} e_{1}-\sigma_{2} e_{2}-\cdots-\sigma_{n-1} e_{n-1}$

Or, equivalently in matrix form,

$\dot{z}=\left[\begin{array}{ccccc}0 & 1 & 0 & \ldots & 0 \\ 0 & 0 & 1 & \ldots & 0 \\ \vdots & \vdots & \vdots & \ldots & \vdots \\ 0 & 0 & 0 & \ldots & 1 \\ -\sigma_{1} & -\sigma_{2} & -\sigma_{3} & \ldots & -\sigma_{n-1}\end{array}\right] z$

Where, $z=\left[\begin{array}{llll}e_{1} & e_{2} & \cdots & e_{n-1}\end{array}\right]^{T}$

These are the $n-m$ to $n-1$ first-order reduction differential equations of sliding mode. The root of the following equation shows the poles.

$\lambda^{n-1}+\sigma_{n-1} \lambda^{n-2}+\cdots+\sigma_{2} \lambda+\sigma_{1}=0$

The system response is depends on the chosen values $\sigma_{1}, \sigma_{2}, \cdots, \sigma_{n-1}$ of the switching surface.

The sliding surface for this system can be represented as

$s(x)=\left[\begin{array}{ll}\sigma_{1} & 1\end{array}\right] e=0$

Or, equivalently,

$\sigma_{1} e_{1}+e_{2}=0$

The dynamics of the system in sliding are described by

$\dot{z}=-\sigma_{1} z$,

For stability select $\sigma_{1}>0$.

In order to attain the controller objective such that to drive the pant state to the sliding surface and maintain it on the surface for all time, a generalized Lyapunov approach is used [11].

$V=0.5 s^{2}$

The system should be stable, the sufficient condition is

$-\frac{d}{d t}\left(\frac{1}{2} s^{2}\right)=s \dot{s}<0$

We consider the controller structure of the form

$u=k^{ \pm}{ }_{1} e_{1}+k^{ \pm}{ }_{2} e_{2}+\cdots+k^{ \pm}{ }_{n} e_{n}$

Where $k_{i}^{ \pm}$are the feedback gains to be determined so that the condition $\sigma \dot{\sigma}<0$ is satisfied. To determine so that the feedback gains, we substitute $u$, given by above equation, into the expression $\sigma \dot{\sigma}$ and utilize to get

$$
\begin{aligned}
& s \dot{s}=s\left[\begin{array}{llll}
\sigma_{1} & \sigma_{2} & \cdots & 1
\end{array}\right] \dot{e} \\
& =s\left(\sigma_{1} \dot{e}_{1}+\cdots+\sigma_{n-1} \dot{e}_{n-1}+\dot{e_{n}}\right) \\
& =s\left(\sigma_{1} e_{2}+\cdots+\sigma_{n-1} e_{n}+\dot{e_{n}}\right) \\
& =s\left(\sigma_{1} e_{2}+\cdots+\sigma_{n-1} e_{n}-a_{0} e_{1}-\cdots-a_{n-1} e_{n}+u\right) \\
& =s\left(\sigma_{1} e_{2}+\cdots+\sigma_{n-1} e_{n}-a_{0} e_{1}-\cdots-a_{n-1} e_{n}+k_{1}^{ \pm} e_{1}+\cdots+k_{n}^{ \pm} e_{n}\right)
\end{aligned}
$$

Rearranging the terms yields 


$$
s \dot{s}=s e_{1}\left(-a_{0}+k_{1}^{ \pm}\right)+s e_{2}\left(-a_{1}+\sigma_{2}+k_{2}^{ \pm}\right)+\cdots+s e_{n}\left(-a_{n-1}+\sigma_{n-1}+k_{n}^{ \pm}\right)
$$

To satisfy the condition (17)

$s e_{1}\left(-a_{0}+k_{1}^{ \pm}\right)<0$,

$s e_{2}\left(-a_{1}+\sigma_{1} k_{2}^{ \pm}\right)<0$,

$s e_{n}\left(-a_{n-1}+\sigma_{n-1+} k_{n}^{ \pm}\right)<0$

A possible choice of gains that leads to satisfaction of the attractively to the surface condition, $\sigma \dot{\sigma}<0$, is

$k_{1}^{+}<-\left|a_{0}\right|$ if $s e_{1}>0$,

$k_{1}^{+}>\left|a_{0}\right|$ if $s e_{1}<0$,

:

$k_{n}^{+}<-\left|a_{n-1}\right|+\left|\sigma_{n-1}\right|$ if $s e_{n}>0$,

$k_{n}^{-}>-\left|a_{n-1}\right|+\left|\sigma_{n-1}\right|$ if $s e_{n}<0$

The following controller gains also can be used:

$k_{1}^{ \pm}=-\left(\left|a_{0}\right|+\varepsilon\right) \operatorname{sign}\left(x_{1} s\right)$,

$\vdots$

$k_{n}^{ \pm}=-\left(\left|a_{n-1}\right|+\left|\sigma_{n-1}\right|+\varepsilon\right) \operatorname{sign}\left(x_{n} s\right)$,

Where $\varepsilon>0$ is a design parameter. The larger the value of $\varepsilon$ the faster the trajectory converges to the sliding surface.

\section{Fuzzy Gain Scheduling of PID Controller}

Gain scheduling is a technique where PID controller parameters (gains) are tuned during control process, using the fuzzy rule base system. Fuzzy controller can be used as a part of control loop or as a supervisor. In gain scheduling scheme fuzzy enhances the performance of PID [13].

In this, a fuzzy supervisor with two inputs-three outputs is used to change the controller parameters as per the changing operation conditions and need of plant. The input variables are error and change in error and the outputs are $K_{p 1}, K_{i 1}$ and $K_{d 1}$. The overall scheme is shown in Figure 2.

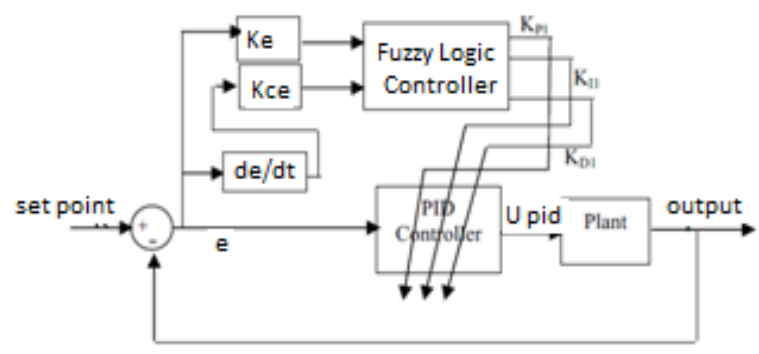

Figure 2 - PID Control System with Fuzzy Gain Scheduling

The PID parameters are tuned by using fuzzy inference, which provide a nonlinear mapping from the error and derivative of error to PID parameters.

The fuzzy logic control has four basic components [14]: 
I. Fuzzification: This converts input data into suitable linguistic values. As shown in Figure 2, there are two inputs to the controller: error and rate change of the error signals. The error is defined as:

$e(t)=r(t)-y(t)=w^{*}-w$

Change in error is defined as it follows:

$\Delta e(t)=e(t)-e(t-1)$

Where $r(t)$ is the reference input, $y(t)$ is the output, $e(t)$ is the error signal, and $\Delta e(t)$ is the rate of error. The five input trapezoidal and triangular and four output triangular membership functions of the fuzzy self-tuning are shown in Figures (3) and (4). For the system under study the universe of discourse for both $e(t)$ and $\Delta e(t)$ are normalized in the range $[-1,1]$, and the linguistic labels are Negative High(NH),Negative Low(NL) , Zero(ZO), Positive Low(PL), Positive High(PH), and linguistic variables for $K_{p 1}, K_{i 1}$ and $K_{d 1}$ are Zero(ZO), Low(L), Medium(M), High(H) and normalized in the range[0,1].

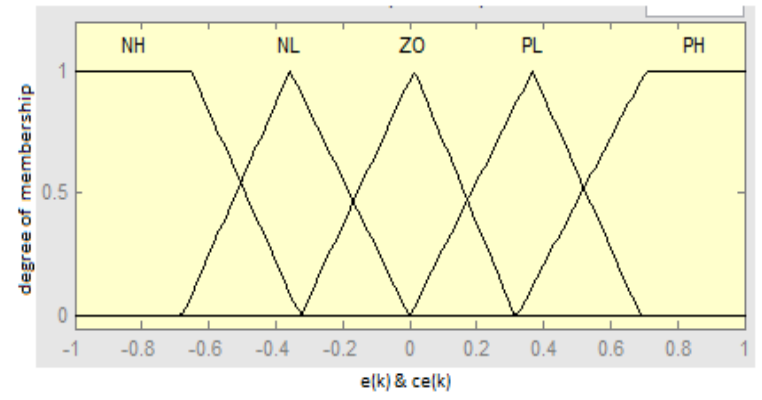

Figure 3. Membership Function for $e(t)$ and $\Delta e(t)$

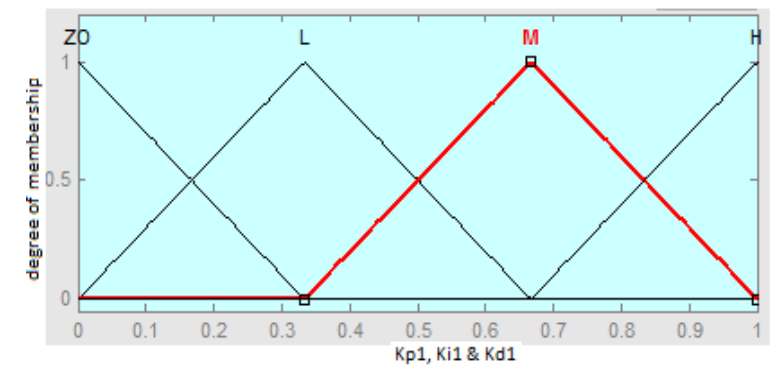

Figuer 4. Membership Functions for $K_{p 1} K_{i 1}$ and $K_{d 1}$

II. Rule Base: Fuzzy PID controllers are knowledge based systems, so rules are formed based on what type of time response is desired from the system. These rules are framed based on experience of operator [15][16]. The parameters $K_{p 1} K_{i 1}$ and $K_{d 1}$ for proposed controller are determined by a set of fuzzy rules as:

If $e(k)$ is $A j$ and ce $(k)$ is $B j$ then $K_{p 1}$ is $C j, K_{i 1}$ is $D j$ and $K_{d 1}$ is $E_{j} j=1,2,3 \ldots$ $m$ and $m$, is the number of rules

Here, $A_{j}, B_{j} C_{j}, D_{j}$ and $E_{j}$ are fuzzy sets of the corresponding sets. The membership functions for these variables are shown in Figures (3) and (4).

The gains $K_{p 1} K_{i 1}$ and $K_{d 1}$ of PID controller are so chosen to achieve a fast rising time, smaller overshoot and no steady state error for the system.

Figure 5 represents the desired time response. The time response is divided in three parts: below set point, the error is positive and above set point the error is negative and around set point error is nearly zero. In accordance with this response, the rules must be written. Initially, i.e. around a1, when error is positive, a big control signal is required to 
achieve a fast rise time. The PID controller should have a large proportional gain, a large integral gain and derivative gain is zero when a big control action is required.

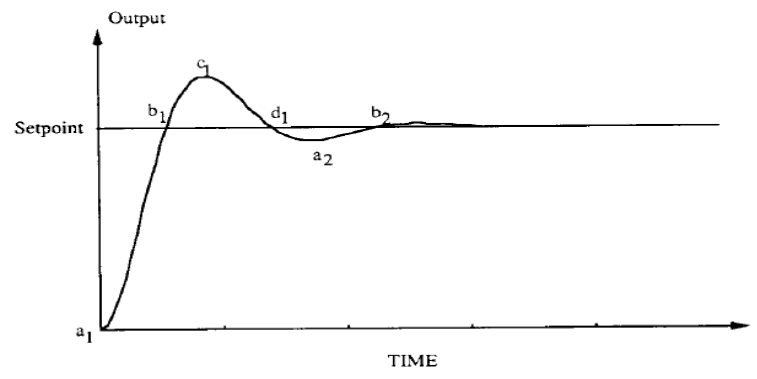

Figure 5. Unit Step Response for Controlled System

Therefore rule around a1 written as follows:

If $e(k)$ is $P H$ and ce $(k)$ is $Z O$ then $K_{p 1}$ is $H, K_{i 1}$ is $H$ and $K_{d 1}$ is $Z O$

Now, around b1, when error is nearly zero, a small control signal is needed, otherwise a large over shoot occurs i.e. $K_{p 1}$ is small, $K_{i 1}$ is small and $K_{d 1}$ should be large. So, the rule for this case is as follows:

If $e(k)$ is $Z O$ and $c e(k)$ is $N H$ then $K_{p 1}$ is $L, K_{i 1}$ is $L$ and $K_{d 1}$ is $H$

By following the same procedure, the others rules can be written, which is summarized in Table (1, 2 and 3$)$.

Table 1. Tuning Rule for $K_{p}$

\begin{tabular}{|l|l|l|l|l|l|}
\hline Ce/e & NH & NL & ZO & PL & PH \\
\hline NH & L & H & H & M & L \\
\hline NL & L & M & H & M & L \\
\hline ZO & L & L & M & L & ZO \\
\hline PL & L & M & M & M & L \\
\hline PH & L & H & H & M & B \\
\hline
\end{tabular}

Table 2. Tuning Rule for $K_{i}$

\begin{tabular}{|c|c|c|c|c|c|}
\hline Ce/e & NH & NL & ZO & PL & PH \\
\hline NH & H & M & ZO & L & L \\
\hline NL & H & M & ZO & L & H \\
\hline ZO & H & H & H & H & H \\
\hline PL & H & H & L & M & H \\
\hline PH & H & M & L & M & ZO \\
\hline
\end{tabular}

Table 3: Tuning rule for $K_{d}$

\begin{tabular}{|c|c|c|c|c|c|}
\hline $\boldsymbol{C} e / \boldsymbol{e}$ & NH & NL & ZO & PL & PH \\
\hline NH & ZO & H & H & H & L \\
\hline
\end{tabular}




\begin{tabular}{|c|c|c|c|c|c|}
\hline NL & ZO & H & H & M & M \\
\hline ZO & L & L & H & L & H \\
\hline PL & L & H & H & M & M \\
\hline PH & L & H & H & H & L \\
\hline
\end{tabular}

III. Defuzzification: Finally the defuzzification process converts the fuzzy output into crisp control signal [17][18]. The mostly used defuzzification method is 'center of gravity' or 'center of area':

$u(n T)=\frac{\sum_{j=1}^{n} u\left(u_{j}\right) u_{j}}{\sum_{j=1}^{n} u\left(u_{j}\right)}$

Where $u\left(u_{j}\right)$ member ship grade of the element $u_{j}, u(n T)$ is the fuzzy control output, $\mathrm{n}$ is the number of discrete values on the universe of discourse.

\section{Fuzzy Supervisory Hybrid Control}

A fuzzy supervisory system is used to calculate the value $k$. However, SMC controllers are better able to control and gives fast dynamic response but the drawback associated with them is chattering in steady state. Hence, to reduce this chattering a fuzzy supervisory hybrid system, as shown in Figure. 6, was developed to utilize the advantages of both SMC controller and FGSPID. Figure. 7 shows a switch between the SMC and the FGSPID controller, where the position of the switch depends on the value of $k$.The outputs of the SMC controller and the FGSPID controller are then multiplied by both the values $1-k$ and $k .1-k$ and $k$ are the deciding factors of the blending part of the switching mechanism [6][20]. These factors help in deciding the best level of contribution by each controller action for overall best performance keeping in view that higher control action should produce faster system response.

$U_{\text {hybrid }}=k \cdot U_{S M C}+(1-k) U_{F G S P I D}$
Or
$U_{\text {hybrid }}=k \cdot U_{F G S P I D}+(1-k) U_{S M C}$

It is obvious that, when the error and its derivative with respect to time in absolute value are large, the hybrid system applies the SMC, which has a fast rise time and a small amount of overshoot, to the system in order to correct the position with respect to the set point. When an error and its derivative with respect to time in absolute value are small, the hybrid system shifts control to the FGSPID, which has better accuracy near the set position \& reduces the chattering which is caused by SMC.

Figure. 8,9,10 shows the supervisory fuzzy inference machine. The membership functions are triangular ones for input and output. Definitions of symbols are: Positive Big (PB), Big (B), medium (M), small (S) and zero (Z).

Rules for supervisory system are defined by table 6 , for example, a rule in the table 5 can be stated as follows: "If absolute value of error is zero and absolute value of the derivative error is zero, then $k$ is positive big." Once the value $k$ is obtained the final control action, is determined by (27). 


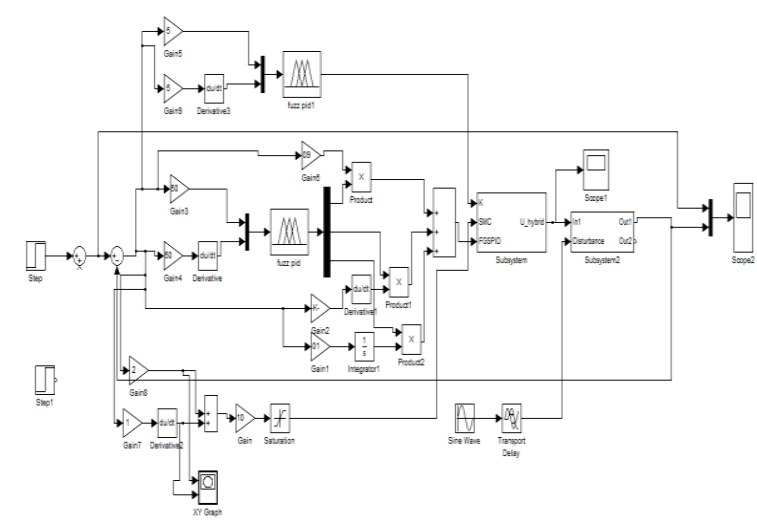

Figure 6. Hybrid Control Simulink Model

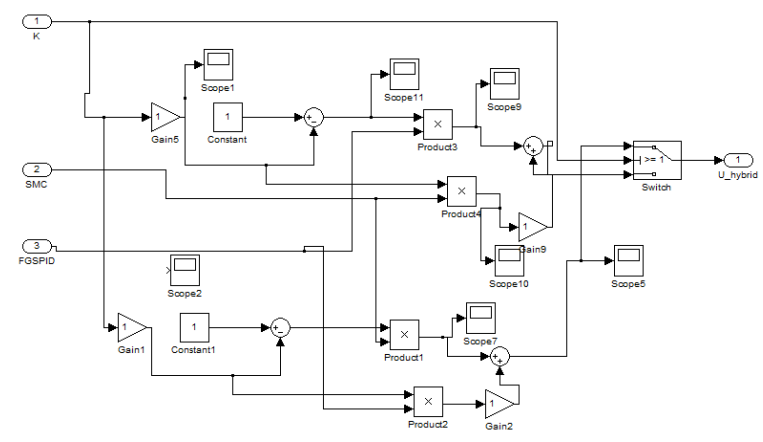

Figure. 7 - Switching Mechanism Simulink Model

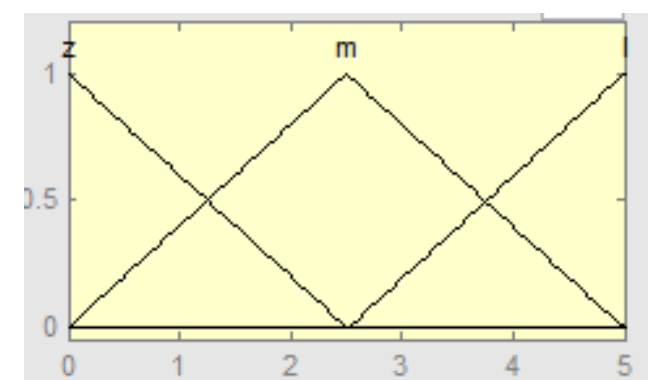

Figure 8. Membership Functions for e

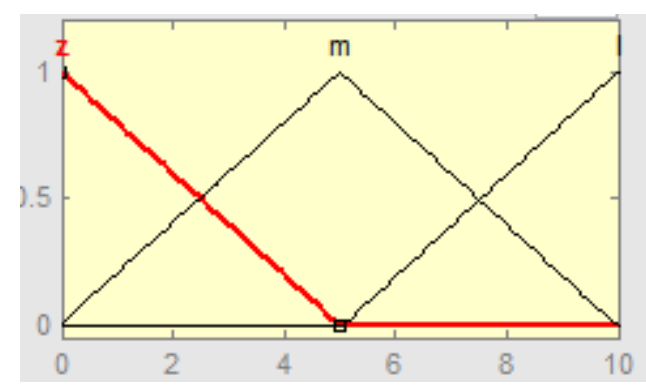

Figure. 9 - Membership Functions for e and ce 


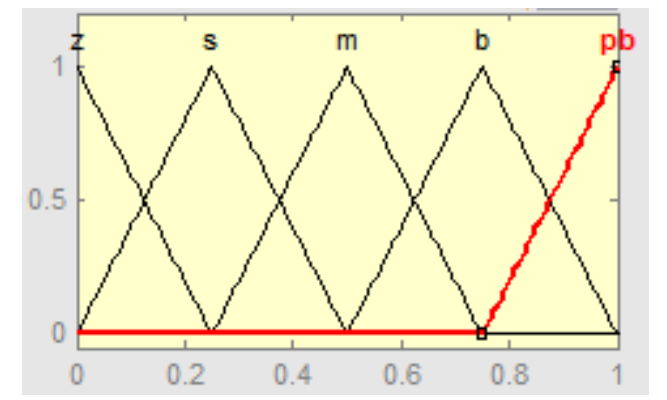

Figure. 10 - Membership Functions for $k$

Table 5: Tuning Rule for $k$

\begin{tabular}{|c|c|c|c|}
\hline $\mathrm{ce} / \mathrm{e}$ & $\mathrm{Z}$ & $\mathrm{M}$ & $\mathrm{L}$ \\
\hline $\mathrm{Z}$ & $\mathrm{PB}$ & $\mathrm{B}$ & $\mathrm{M}$ \\
\hline $\mathrm{M}$ & $\mathrm{S}$ & $\mathrm{S}$ & $\mathrm{Z}$ \\
\hline $\mathrm{L}$ & $\mathrm{Z}$ & $\mathrm{Z}$ & $\mathrm{Z}$ \\
\hline
\end{tabular}

\section{Results \& Discussions}

In order to verify the performance of proposed hybrid speed control of DC Motor, computer simulations were performed using Matlab/Simulink and comparison is made with SMC and FGSPID. The ratings and parameters of DC motor used are given in table 4 , and the step reference input is applied to DC Motor model.

The FGSPID is applied by using above rule base table 1, 2, 3 and SMC is applied by considering the switching function as:

$$
s=\sigma e+\dot{e}
$$

The simple control law for SMC is given by

$$
u=-k \operatorname{sgn}(s) \text {, Choosing } \sigma=2 \text { and } k=10 \text {. }
$$

Where, $\sigma$ and $k$ is a positive constant.

Figure 7 (a) shows the simulation results of step response for SMC. This figure show that SMC gives better response but chattering in control law is present there, Figureure 7(b). Second simulation was performed with FGSPID control, the results shows that poor response is obtained as compared to SMC Figure 8(a), but during steady state no chattering is there Figure 8(b).

Third simulation was performed with the proposed Hybrid Fuzzy-Sliding Mode Control based on SMC \& FGSPID. Simulation parameters are the same as in the first case and the simulation results are given in Figure. 9 (a) shows tracking precision is about the same but the real improvement can be noticed on the control signal discontinuities and levels figure 9 (b). Chattering is suppressed, also.

From these results it can be seen that Hybrid Fuzzy-Sliding Mode Control have better response, less rise time, no overshoot, fast response and zero steady state error as compared to FGSPID and also less chattering as compared to SMC.Figure 10, shows the sliding surface of SMC and hybrid.

Table 4. Ratings and Nominal Parameters of DC Motor

\begin{tabular}{|c|c|c|c|c|}
\hline$L$ & $0.001 \mathrm{mH}$ & & $R$ & $0.5 \mathrm{ohm}$ \\
\hline$J$ & $0.001 \mathrm{kgm}^{2}$ & & $k_{m}$ & 0.001 Vsrad-1 \\
\hline$K_{e}$ & $0.008 \mathrm{NmA}-1$ & & $B$ & 0.01 Nmsrad-1 \\
\hline
\end{tabular}




\section{Conclusion}

A novel design methodology that mixes the SMC and the FGSPID controllers in an intelligent way is presented in this paper. Thus a new intelligent hybrid controller has been achieved. A switching \& mixing mechanism that depends on the value of $k$, which the output of fuzzy supervisory system is presented. Simulations carried out shows that the new hybrid SMC-FGSPID controllers have provided 'better' system responses in terms of transient and steady-state performances when compared to pure SMC or the pure FGSPID controller applications.

Table 6. Performance Comparison of SMC, FGSPID and Hybrid

\begin{tabular}{|l|l|l|l|}
\hline & $T_{r}(\mathrm{sec})$ & $M_{p}(\%)$ & $e_{s S}(\%)$ \\
\hline SMC & 1.25 & 0 & 0 \\
\hline FGSPID & 4.8 & 0 & 0 \\
\hline Hybrid & 1.9 & 0 & 0 \\
\hline
\end{tabular}

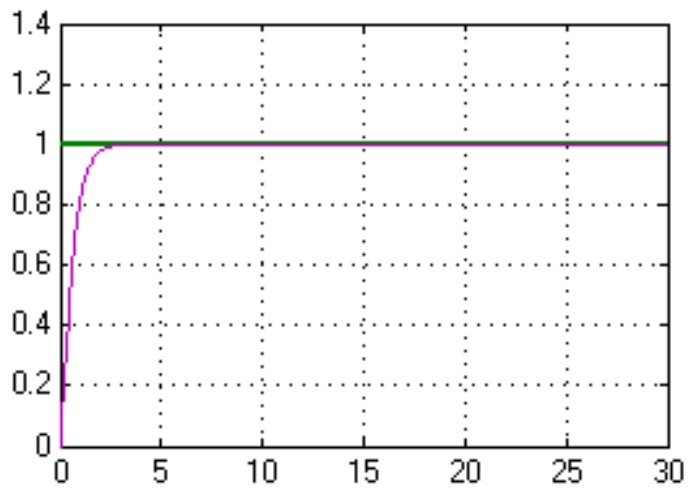

(a) Step Response Using SMC

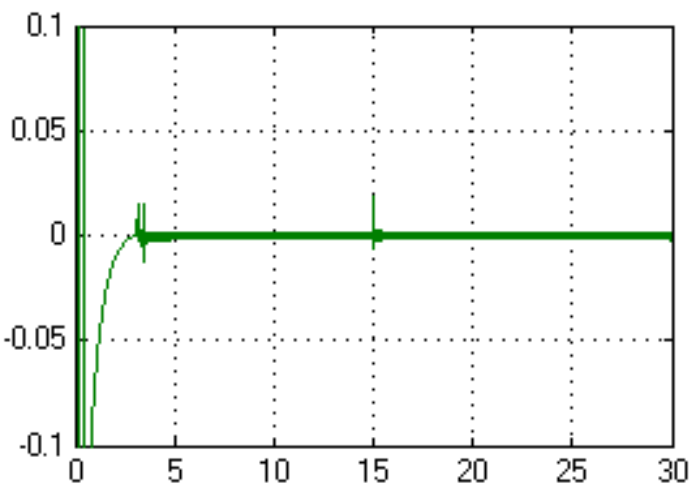

(b) Control Signal

Figure 7

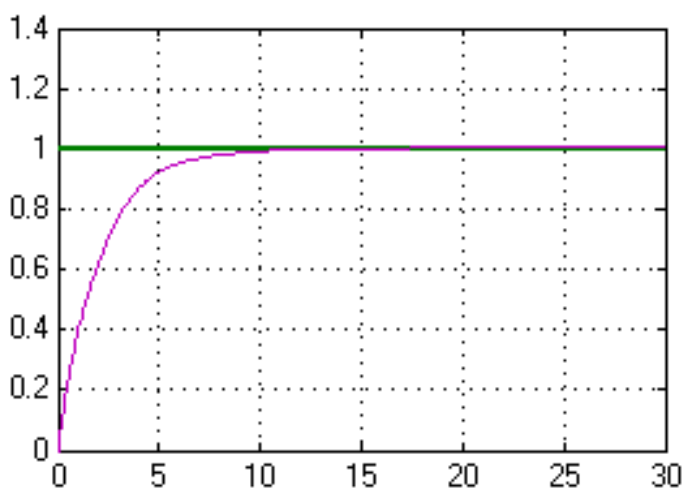

(a) - Step Response Using FGSPID Controller

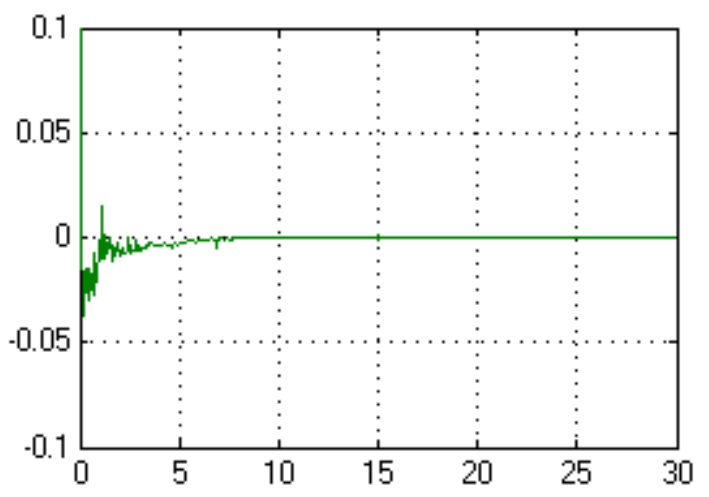

(b) Control Signal

Figure 8 


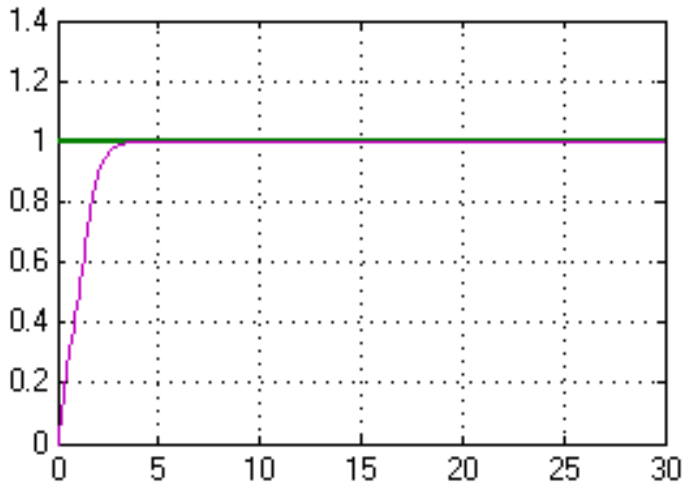

(a) - Step Response Using HYBRID Controller

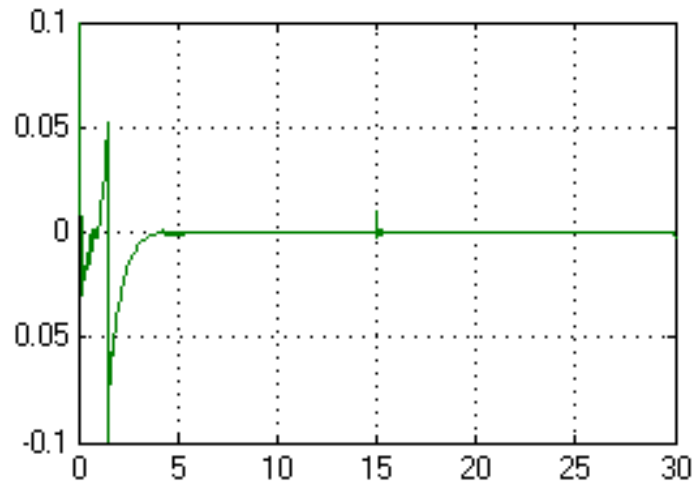

(b) Control Signal

\section{Figure 8}

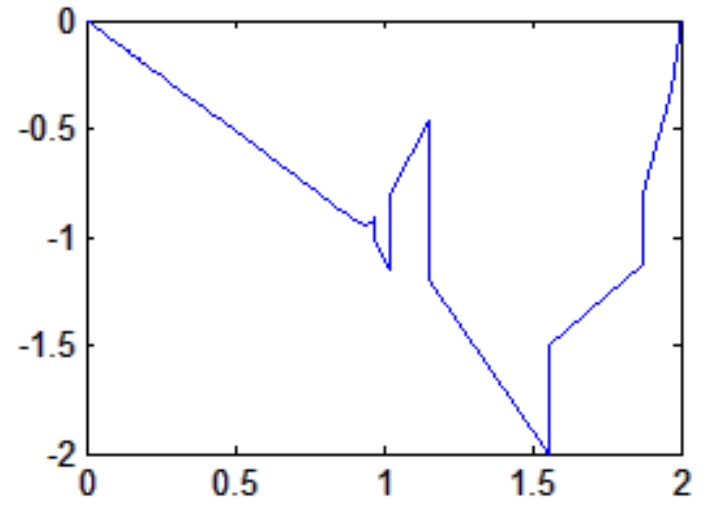

(a) Sliding Surface for SMC

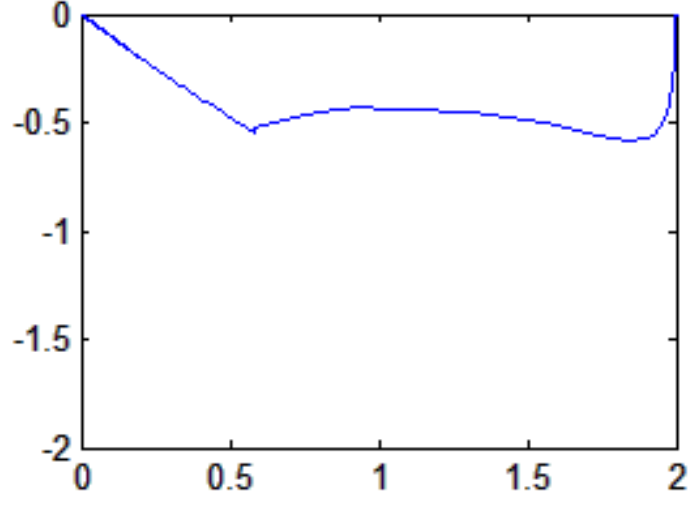

(b) Sliding Surface for HYBRID Controller

Figure 9

\section{References}

[1] K.J. Åström, and T. Hagglund: PID Controllers: Theory, design and tuning. ISA Pres, Research Triangle Park, North Carolina 1995.

[2] D.P Kwok, P. Tam, C.K Li, P. Wang: Linguistic PID controllers. Proceedings of the 11th World Congress, Tallin, Estonia, 7, 1990, pp. 192-197.

[3] T. Brehm, K.S. Rattan: Hybrid fuzzy logic PID controller. Proceeding of the, IEEE National Aerospace and Electronics Conference, Vol.2, 1993, pp. 807-813.

[4] M. J. Sun: Hybrid fuzzy proportiona integral plus conventional derivative control of linear and nonlinear systems. IEEE Trans. On Industrial Electronics 48(6), 2001, pp.1109-1117.

[5] R. Ketata, D.D. Geest, A .Titli: Fuzzy controller: design, evaluation, parallel and hierarchical combination with a PID controller. Fuzzy Sets and Systems, (71), 1995, pp.113-129.

[6] Priyanka Sharma, Er. Silki Baghla: Performance of Hybrid Fuzzy and Fuzzy Self Tuning PID Controller for any Order Transfer Function. International Journal of Advanced Research in Computer Science and Software Engineering, Vol 4, Issue 1, January 2014 ISSN: 2277 128X

[7] Mahmoud Moosavi Mehdi Eram, Arzhang Khajeh, Omid Mahmoudi, Farzin Piltan: Design New Artificial Intelligence Base Modified PID Hybrid Controller for Highly Nonlinear System. International Journal of Advanced Science and Technology, Vol. 57, August 2013. 
[8] F. Barrero, A. González, A. Torralba, E. Galván, L. G. Franquelo: Speed Control of Induction Motors Using a Novel Fuzzy Sliding-Mode Structure, IEEE TRANSACTIONS ON FUZZY SYSTEMS, VOL.10, NO. 3, JUNE 2002, pp. 375-383

[9] Husain Ahmed ,Arpit Goel, Ankit Uniyal,Anurag Bahuguna, S Rituraj: Patwal.Performance Comparison of PID and Fuzzy Logic Controller Using Different Defuzzification Techniques for Positioning Control of DC Motors.Journal of Information Systems and Communication, ISSN: 0976-8742 \& E-ISSN: 09768750, Vol. 3, Issue1, 2012,pp.-235-238.

[10] K. Ogata: Modern Control Engineering, Second Edition, Prentice-Hall, Inc., (1995).

[11] [11] V. I. Utkin: Sliding mode control design principles and applications to electric drives, IEEE Trans. Ind. Application, vol. 40, Feb. 1993.

[12] A. Suyitno, J. Fujikawa, H.Kobayashi, Y. Dote: Variable-structured robust controller by fuzzy logic for servomotors, IEEE Trans. Ind. Electron., vol. 40, Feb. 1993.

[13] C.C. Hang, K.J. Astrom and W.K. Ho: Refinements of the Ziegler-Nichols Tuning Formula. IEEE Control Theory and Applications, Vol. 138, No. 2, Mar. 1991, pp. 111-118.

[14] L. Wang, M. Tian , Y. Gao: Fuzzy Self-adapting PID Control of PMSM Servo System, IEEE International Electric Machines \& Drives Conference, Vol. 1, May.2007, pp. 860-863.

[15] F. Barrero, E. Galván, A. Torralba, L. G. Franquelo: Fuzzy self tuning system for induction motor controllers, in Eur. Power Electronics Conf., Seville, Spain, Sept. 1995.

[16] F. Barrero, A. Torralba, E. Galván, and L. G. Franquelo: A switching fuzzy controller for induction motors with self-tuning capability, in IECON-95, Orlando, FL, Nov. 1995.

[17] Z.Y. Zhao, M. Tomizuka, S. Isaka: Fuzzy gain-scheduling of PID controllers, IEEE Trans. Syst., Man, Cybern, Vol. 23, 1993, pp.1392-1398.

[18] L. A. Zadeh: Fuzzy sets, Information Control, vol. 8, (1965), pp. 338-353.

[19] T. C. Chen , J. U. Hsu: A fuzzy sliding-mode controller for induction motor position control, in Proc. 20th Int. Conf. Industrial Electronics, Control Instrumentation, New York, 1994, pp. 44-49.

[20] Pornjit Pratumsuwan, Siripun Thongchai, Surapun Tansriwong: A Hybrid of Fuzzy and ProportionalIntegral-Derivative Controller for Electro-Hydraulic Position Servo System. Energy Research Journal 1 (2), 2010, pp. 62-67, ISSN 1949-0151 ¿C 2010 Science Publication.

\section{Authors}

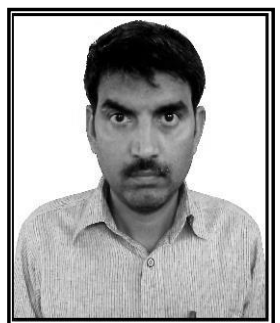

Husain Ahmed, he was born on 28th March 1974 at Deoband (INDIA). He has obtained his B.E. in Electrical engineering \& M. Tech. In Instrumentation \& control from Aligarh Muslim University, Aligarh, India. He is pursuing his Ph.D. from Mewar University, Rajasthan, India. He is currently worked as an Assistant Prof. in DIT University, Dehradun, Uttarakhand, India.

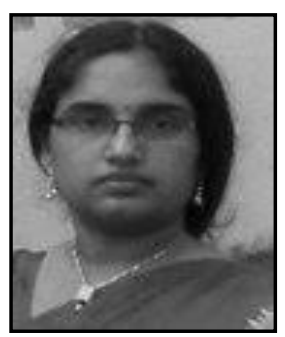

Abha Rajoriya, she received Ph.D. degrees in electrical engineering from the Indian Institute of Technology, Roorkee, India in 2012. Currently she is head of department of electrical \& electronics engineering of Jai Narayan College of engineering College, Bhopal, MP, India. Her research interest includes power system, fuzzy control system. 
International Journal of Grid and Distributed Computing Vol.9, No.5 (2016) 